\title{
Primary Therapy of Early Breast Cancer: \\ Evidence, Controversies, Consensus
}

Spectrum of Opinion of German Specialists on the 16th St. Gallen

International Breast Cancer Conference (Vienna 2019)

\section{Behandlung von Patientinnen mit frühem Mammakarzinom: Evidenz, Kontroversen, Konsens}

\author{
Meinungsbild deutscher Experten zur 16. Internationalen St.-Gallen- \\ Konsensus-Konferenz (Wien 2019)
}

()ㅜ(i) $(9)$

\author{
Authors \\ Affiliations \\ 1 Klinik für Gynäkologie und Geburtshilfe, interdisziplinäres \\ Brustzentrum, HELIOS Klinikum Berlin Buch, Berlin, \\ Germany \\ 2 Klinik und Poliklinik für Gynäkologie, Martin-Luther- \\ Universität, Halle-Wittenberg, Halle/Saale, Germany \\ 3 Interdisziplinäres Brustkrebszentrum, Frauenklinik, \\ Klinikum Landshut, Landshut, Germany \\ 4 Interdisziplinäres Brustzentrum, Frauenklinik, Rotkreuz- \\ klinikum München, München, Germany \\ 5 Universitäts-Frauenklinik Tübingen, Tübingen, Germany \\ 6 Interdisziplinäres Brustzentrum Kempten - Allgäu \\ (IBZK-A), Klinik für Frauenheilkunde und Geburtshilfe, \\ Klinikum Kempten, Klinikverbund Kempten-Oberallgäu, \\ Kempten, Germany \\ 7 Brustzentrum, Frauenklinik der Universität München \\ (LMU), München, Germany \\ 8 Brustkrebs Deutschland e. V. \\ 9 Brustzentrum, Frauenklinik, Katholisches Klinikum Mainz, \\ Mainz, Germany \\ 10 Universitätsfrauenklinik Ulm, Brustzentrum, Ulm, \\ Germany \\ 11 Klinik für Gynäkologie und Geburtshilfe, Sana-Klinikum \\ Offenbach, Offenbach, Germany
}

Michael Untch ${ }^{*}$, Christoph Thomssen ${ }^{2 *}$, Ingo Bauerfeind ${ }^{3 * *}$, Michael Braun $^{4 * *}$, Sara Y. Brucker ${ }^{5 * \#,}$ Ricardo Felberbaum ${ }^{6 * *}$, Friederike Hagemann ${ }^{7 * *}$, Renate Haidinger ${ }^{8 * *}$, Arnd Hönig ${ }^{9 * *}$, Jens Huober ${ }^{10 * \#}$, Christian Jackisch ${ }^{11 *}$, Hans-Christian Kolberg ${ }^{12 * *}$, Cornelia Kolberg-Liedtke ${ }^{13 *}$, Thorsten Kühn ${ }^{14 *}$, Diana Lüftner $^{15 *}$, Nicolai Maass ${ }^{16 * *}$, Toralf Reimer ${ }^{17 * *}$, Andreas Schneeweiss ${ }^{18 *}$, Eva Schumacher-Wulf ${ }^{19 * *}$, Florian Schütz ${ }^{20 * *}$, Marc Thill ${ }^{21}$, Rachel Wuerstlein ${ }^{7 * *}$, Peter A. Fasching ${ }^{22 *}$, Nadia Harbeck ${ }^{7 * \#}$

\footnotetext{
* Writing Committee

** Steering Committee

* $\quad$ St. Gallen Panel Expert
}

12 Brustzentrum, Klinik für Gynäkologie und Geburtshilfe, Marienhospital Bottrop gGmbH, Bottrop, Germany

13 Charité - Universitätsmedizin Berlin, Campus Mitte, Berlin, Germany

14 Klinik für Frauenheilkunde und Geburtshilfe, Klinikum Esslingen, Esslingen, Germany

15 Medizinische Klinik mit Schwerpunkt Hämatologie, Onkologie und Tumorimmunologie, Charité Campus Benjamin Franklin, Berlin, Germany

16 Brustzentrum, Klinik für Gynäkologie und Geburtshilfe, Universitätsklinikum Schleswig-Holstein, Kiel, Germany

17 Brustzentrum, Universitätsfrauenklinik und Poliklinik, Klinikum Südstadt Rostock, Rostock, Germany

18 Sektionsleiter Gynäkologische Onkologie des Universitätsklinikum (UKHD), Fellow des Deutschen Krebsforschungszentrum (DKFZ), Nationales Centrum für Tumorerkrankungen (NCT), Universitätsklinikum Heidelberg, Heidelberg, Germany

19 Mamma Mia! Das Brustkrebsmagazin, Kronberg, Germany

20 Brustzentrum, Sektion Senologie, UniversitätsKlinikum Heidelberg, Heidelberg, Germany

21 Klinik für Gynäkologie und Gynäkologische Onkologie, Agaplesion Markus Krankenhaus, Frankfurt/Main, Germany

22 Frauenklinik des Universitätsklinikums Erlangen, Comprehensive Cancer Center Erlangen-EMN, Friedrich-Alexander Universität Erlangen-Nürnberg, Erlangen, Germany 
Key words

St. Gallen consensus 2019, early breast cancer, locoregional therapy, axilla, neoadjuvant treatment, systemic therapy

Schlüsselwörter

St.-Gallen-Konsensus 2019, frühes Mammakarzinom, lokoregionäre Therapie, Axilla, neoadjuvante Therapie, Systemtherapie

received $\quad 3.4 .2019$

revised 20.4.2019

accepted 21.4.2019

Bibliography

DOI https://doi.org/10.1055/a-0897-6457

Geburtsh Frauenheilk 2019; 79: 591-604 @ Georg Thieme

Verlag KG Stuttgart · New York | ISSN 0016-5751

Correspondence

Prof. Dr. med. Michael Untch

Klinik für Gynäkologie, gynäkologische Onkologie und Geburtshilfe mit Perinatalzentrum Level I, interdisziplinäres Brustzentrum, HELIOS Klinikum Berlin Buch Schwanebecker Chaussee 50, 13125 Berlin, Germany michael.untch@helios-gesundheit.de

$\Theta$

Deutsche Version unter:

https://doi.org/10.1055/a-0897-6457

\section{ABSTRACT}

The results of the international St. Gallen Consensus Conference for the treatment of patients with primary breast cancer were discussed this year by a working group of leading breast cancer experts in view of the therapy recommendations for everyday clinical practice in Germany. Three of the breast can- cer experts are also members of this year's St. Gallen panel. The comparison of the St. Gallen recommendations with the annually updated treatment recommendations of the AGO 2019 as well as the S3 guideline is useful, since the recommendations of the St. Gallen panel represent the opinions of experts from various countries and disciplines. The recommendations of the $\mathrm{S} 3$ guideline and AGO are based on evidence-based research of the literature. This year's 16th St. Gallen conference featured the motto "Magnitude of clinical benefit". In addition to the evidence-based data, each therapeutic decision must also undergo a benefit/risk assessment of the patient's individual situation and be discussed with the patient.

\section{ZUSAMMENFASSUNG}

Die Ergebnisse der internationalen St.-Gallen-KonsensusKonferenz zur Behandlung des primären Mammakarzinoms wurden auch dieses Jahr von einer Arbeitsgruppe führender Brustkrebsexperten vor dem Hintergrund der Therapieempfehlungen für den Klinikalltag in Deutschland diskutiert. Drei der Brustkrebsexperten sind zugleich Mitglieder des diesjährigen St.-Gallen-Panels. Der Vergleich der St.-Gallen-Empfehlungen mit den jährlich aktualisierten Therapieempfehlungen der Arbeitsgemeinschaft Gynäkologische Onkologie (AGOMamma 2019) sowie der S3-Leitlinie ist sinnvoll, da die Empfehlungen des St.-Gallen-Panels ein Meinungsbild von Experten unterschiedlicher Länder und Fachdisziplinen darstellen. Die Empfehlungen der S3-Leitlinie und AGO basieren dagegen auf einer evidenzbasierten Literaturrecherche. Die diesjährige 16. St.-Gallen-Konferenz stand unter dem Motto „Magnitude of clinical benefit“. Neben der evidenzbasierten Grundlage muss jede Therapieentscheidung auch einer Nutzen-RisikoAbwägung für die individuelle Situation einer Patientin unterzogen und mit der Patientin besprochen werden.

\section{Introduction}

This year's 16th St. Gallen Conference on the "Primary treatment of early breast cancer" featured the motto "Estimating the magnitude of clinical benefit of local and systemic therapies in patients with Early Breast Cancer". The objective was to evaluate not only the relative benefit of a diagnostic or therapeutic intervention on the basis of evidence but also to make recommendations based on the potential absolute benefit (and possibly adverse effects, including long-term side effects) for the individual disease situation of a patient with early breast cancer.

This year's St. Gallen consensus panel was made up of more than 50 breast cancer experts from 23 countries. Five panel members came from Germany ( $\triangleright$ Table 1 ). The St. Gallen recommendations are based on a vote by the panelists. They answered the questions to be voted on with "yes" (agreement), "no" (rejection) or "abstention" (no opinion possible). In the case of other questions, it was possible to decide between several options available.
The objective is to develop a practice-based agreement of the majority of panel members in order to generate an international consensus for everyday clinical practice.

Since the panelists represent different areas of expertise and countries with different healthcare systems and resources, the consensus generally represents the opinions of these experts, even if the votes of the panel members are taking the currently available evidence into account. For an overview of the voting results, see also the article: [1]. In view of this, a German working group has already been commenting for several years on the voting results of the St. Gallen panelists in view of the current therapeutic recommendations of the National Guideline Commission of the German Society of Gynecology and Obstetrics (AGO) [2] which updates its recommendations every year. 
- Table 1 International St. Gallen Panel 2019 - Participants of the international St. Gallen Consensus Panel.

Chair: Giuseppe Curigliano (Italy), Eric P. Winer (USA)

Consensus Writing Committee: Harold J Burstein (USA), Marco Colleoni (Italy), Giuseppe Curigliano (Italy), Carsten Denkert (Germany), Peter Dubsky (Austria/Switzerland), Michael Gnant (Austria), Sibylle Loibl (Germany), Martine Piccart-Gebhart (Belgium), Philip Poortmans (Netherlands/France), Meredith Regan (USA), Hans-Jörg Senn (Switzerland), Beat Thürlimann (Switzerland), Eric P. Winer (USA)
- Harold J. Burstein (USA)
- Viviana Galimberti (Italy)
- Fabrice André (France)
- Heba Gamal (Egypt)
- Philip Poortmans (Netherlands/France)
- Jonas Bergh (Sweden)
- Judy Garber (USA)
- Kathleen Pritchard (Canada)
- Hervé Bonnefoi (France)
- William J. Gradishar (USA)
- Karen Gelmon (Canada)
- Meredith Regan (USA)
- Sara Y. Brucker (Germany)
- Fatima Cardoso (Portugal)
- Lisa Carey (USA)
- Eva Ciruelos (Spain)
- Marco Colleoni (Italy)
- Giuseppe Curigliano (Italy)
- Suzette Delaloge (France)
- Carsten Denkert (Germany)
- Bahadir Gulluoglu (Turkey)
- Nadia Harbeck (Germany)
- Emiel J. T. Rutgers (Netherlands)
- Felix Sedlmayer (Austria)
- Daniel F. Hayes (USA)
- Chiun-Sheng Huang (Taiwan)
- Vladimir Semiglazov (Russia)
- Zhiming Shao (PR China)
- Ian Smith (Great Britain)
- Jens Huober (Germany)
- Zefei Jiang (PR China)
- Per Karlsson (Sweden)
- Petra Tesarova (Czech Republic)
- Beat Thürlimann (Switzerland)
- Angelo Di Leo (Italy)
- Peter Dubsky (Austria/Switzerland)
- Eun Sook Lee (Korea)
- Sibylle Loibl (Germany)
- Monica Morrow (USA)
- Bent Ejlertsen (Denmark)
- Florian Fitzal (Austria)
- Prudence Francis (Australia)
- Kent C. Osborne (USA)
- Olivia Pagani (Switzerland)
- Masakazu Toi (Japan)
- Andrew Tutt (Great Britain)
- Giuseppe Viale (Italy)
- Toru Watanabe (Japan)
- Eric P. Winer (USA)
- Timothy Whelan (Canada)
- Ann H. Patridge (USA)
- Martine Piccart-Gebhart (Belgium)

\section{Surgical Issues}

\section{Importance of margins}

The surgical issues focused, among other things, on the importance of the margin for a possible subsequent reexcision or mastectomy, in order to achieve complete tumour resection. Two years ago - at the St. Gallen Consensus Meeting 2017 - a majority of the panel had voted that, in the case of an unifocal invasive residual tumour, resection with "no ink on tumour" is sufficient to avoid subsequent surgery. This year, a majority of panelists confirmed this vote $(83.3 \%$ ) for multifocal lesions as well - provided that the patient receives adjuvant radiation. The result of the vote corresponds to the current recommendations of the AGO (Arbeitsgemeinschaft Gynäkologische Onkologie [committee of gynaecological oncology]) [2].

According to the majority vote of the St. Gallen panelists (73.3\%), "No ink on tumour" also applies to patients with invasive lobular breast cancer irrespective of whether there are also extensive $(62.5 \%)$ intraductal components (EIC: extended intraductal component). The German expert group agrees and adds that a concomitant ductal carcinoma in situ (DCIS) should always be completely removed. An evidence-based minimal distance for the extensive DCIS is currently not defined. The German experts stress that the prognosis is influenced by the invasive tumour and not by the DCIS.

In the case of a focal resection margin involvement of $<4 \mathrm{~mm}$ for DCIS or $<1 \mathrm{~mm}$ in width for the invasive carcinoma, just under half of the panelists in each case (48.9 and $45.5 \%$ ) voted for a subsequent resection, while 38.3 and $43.2 \%$ rejected this. The German expert group points out that there is currently no evidence for the indication for a subsequent resection by means of a certain extension of the tumour disease on the resection margin. As a general rule, a resection should be performed with free margins. In individual cases and after discussing the benefit and risk of treatment in view of the individual patient characteristics in the tumour board, a subsequent resection can be avoided.

\section{Skin preservation: yes/no?}

The panelists did not reach any consensus regarding the question of whether the skin can be preserved in the case of an infiltration of skin which, however, cannot be detected on imaging. It was additionally discussed whether the nipple-areola complex (NAC) can be preserved when the tumour is located in the retromamillary region. From the viewpoint of the German expert group, the issue only concerns the situation of a nipple-sparing mastectomy (NSM). The German experts point out that in the case of an R0 resection of the primary tumour, preservation of the nipple/areola is possible if this appears to be cosmetically reasonable. It is important that the question of nipple resection will be decided not only based on imaging, but rather clinically and, if necessary, supported by a retroareolar frozen section.

In the case of inflammatory breast cancer, the German expert group agrees with the majority vote (83.0\%) of the St. Gallen panelists that mastectomy with removal of the affected skin should be the surgical standard. This also applies to patients with pathological complete remission ( $\mathrm{pCR}$ ) following primary systemic therapy (PST) for patients with inflammatory breast cancer. 


\section{Surgical Approach in the Axilla at Primary Surgery}

\section{Abstaining from SLNB?}

The German experts and the St. Gallen panelists agree that an ultrasound of the axilla before surgery is useful for deciding whether or not a sentinel lymph node biopsy (SLNB) is indicated.

In patients older than 70 years, the majority (56.5\%) of the St. Gallen panelists do not support SLNB when node status is clinically unsuspicious (cN0) and in the case of a small (T1) luminal A tumour. More than $80 \%$ of the panelists advocated for this in an elderly patient population only on the basis of comorbidities with reduced life expectancy and not due to age per se. For patients with a T2 tumour (luminal A-like), $89.4 \%$ of the St. Gallen panelists still recommend SLNB.

The German expert group points out that SLNB should currently be considered standard for all patients with clinically nodenegative invasive breast cancer (cN0). This also applies to patients with small tumours (cT1) and a luminal A-like subtype and, as a general principle, applies independent of the patient's age. According to the AGO recommendation [2], elderly patients with a life expectancy of at least five years should receive the same therapy as younger patients. In the case of clinically relevant comorbidities or a life expectancy of less than five years, SLNB can be avoided. Each patient should make her own decision in this regard following appropriate explanations and a careful benefit/risk assessment. The data from the randomised studies INSEMA [3] and SOUND [4] should be awaited prior to changing the therapeutic standard. These studies compare a sentinel biopsy vs. no axillary surgery in patients with clinically unsuspicious axilla and planned breast-conserving surgery.

\section{Approach in the axilla in the case of positive sentinel lymph nodes}

For patients with a positive sentinel lymph node (SN), the therapeutic approach in the axilla was discussed based on various scenarios - axillary lymph node dissection (ALND) following mastectomy or breast-conserving surgery if the ACOSOG criteria (see [5]) are not met, and the importance of radiation if ALND is not performed.

A simple majority (47.9\%) of the St. Gallen panelists would perform radiation of the axilla (LDA: lymphatic drainage area) in a patient with a T1/2 breast cancer and 1-2 macrometastatically involved $\mathrm{SNs}(\mathrm{SN}+)$ following mastectomy according to AMAROS (see [6]) - provided that systemic standard therapy is adjuvantly planned. No additional intervention (surgery or radiation) in the axilla is recommended by $12.5 \%$; $16.7 \%$ voted to perform the ALND.

The German expert group does not agree with the vote. Further treatment of the axilla is necessary in this situation. Three therapeutic options are available: Within the goal of tangential field radiation (PMRT: post-mastectomy radiation therapy), radiation of the chest wall with tangents up to $5 \mathrm{~mm}$ below the axillary vein (without ALND) is possible. The other options are radiation of the lymphatic drainage area according to AMAROS [6] or an
ALND. The optimal approach in this situation - following mastectomy - is currently still being investigated in controlled clinical studies. If radiation therapy of the chest wall is planned, ALND can be avoided if the radiation therapy is extended to the axilla.

According to a majority vote of the St. Gallen panelists, an ALND can be avoided in patients following mastectomy with macrometastases in the $\mathrm{SN}$ in the following situations:

- Patient with triple-negative breast cancer (TNBC) and 1-2 positive SNs, if radiation of the LDA is planned (majority vote: $70.8 \%)$.

- Patient with 1-2 positive SNs, positive hormone receptor (ER+ and/or $\mathrm{PR}+$ ) and positive HER2 status (HER2+) as well as planned radiation of the LDA (majority vote: $83.3 \%$ ).

By contrast, a majority of panelists recommend ALND if radiation of the chest wall but not LDA is planned in patients following mastectomy with $1-2$ positive SNs (majority vote: $66.0 \%$ ).

The German expert group recommends in patients with mastectomy and 1-2 positive SLN further treatment of the axilla, either radiation or surgery (ALND). This applies independent of the intrinsic subtype. Currently ongoing studies on the target volume and radiation dose must be awaited in order to be able to make a clear and evidence-based recommendation.

\section{ALND following primary BCT?}

Approximately two-thirds (60.9\%) recommend ALND in patients with a primary tumour $>5 \mathrm{~cm}$ and $1-2$ positive $\mathrm{SNs}$ who have breast-conserving surgery and receive whole-breast radiation therapy (WBRT). The German expert group agrees, since the ACOSOG criteria are not met in this situation [5].

If these patients ( $T>5 \mathrm{~cm}, 1-2 \mathrm{SN}+, \mathrm{BCT}, \mathrm{WBRT})$ additionally receive radiation of the regional lymph nodes, it is possible to refrain from ALND, according to the majority vote of the panelists (73.9\%). The German expert group agrees with the vote of the panelists in an analogous conclusion to the AMAROS data [6] in terms of agreement with "expert level".

\section{Radiation therapy when ALND is avoided}

A simple majority $(41.7 \%)$ of the St. Gallen panelists voted for whole-breast radiation without additional radiation of the axilla (no high tangents) in the case of a patient with primary breast cancer $(T<5 \mathrm{~cm})$ and $1-2$ (macrometastatic) involved sentinel lymph nodes (SN) who have breast-conserving surgery but no ALND. The German expert group does not agree and refers to the AGO recommendation [2]. In this case, tangential field radiation of the breast $5 \mathrm{~mm}$ below the axillary vein which largely includes levels 1 and 2 is recommended ( $\bullet$ Fig. 1 ).

\section{Axillary Staging and Treatment before and after Primary Systemic Therapy (PST)}

\section{cN1 after PST}

Slightly more than half of the St. Gallen panelists (54.2\%) voted to abstain from ALND if 1-2 negative SNs are detected (43.8\% did not agree) after PST (cN0) in patients with clinically and/or sono- 


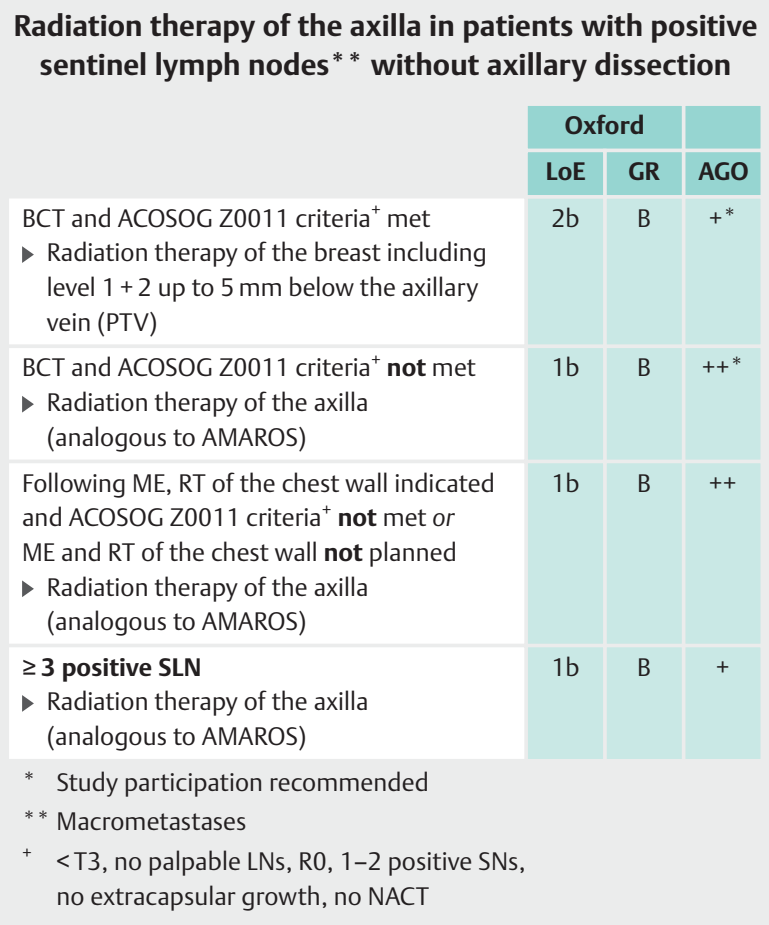

Radiation therapy of the axilla in patients with positive sentinel lymph nodes ${ }^{* *}$ without axillary dissection

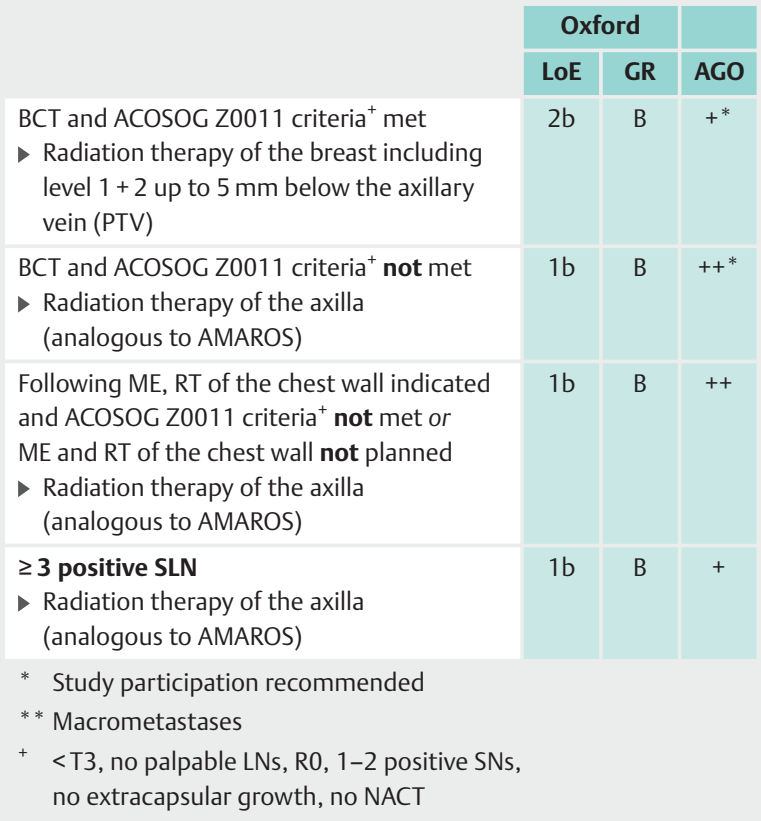

- Fig. 1 AGO recommendation 2019 on the use of radiation therapy in patients with primary invasive breast cancer and positive $\mathrm{SN}$ without ALND [2]. Photo credit: Courtesy of AGO

graphically suspicious axillary lymph nodes before PST (cN1), while nearly all panelists (91.7\%) considered SLNB alone to be sufficient if there are three or more negative SNs.

The German expert group recommends TAD (targeted axillary dissection) with prior clip placement in the lymph node which is histologically positive by core biopsy before PST, in patients with 1-2 negative SNs, because otherwise the false-negative rate (FNR) is too high [2]. If there are three or more negative SNs on frozen section, ALND can be avoided. In patients with 1-2 negative SNs false negative rate is $>10 \%$ and in patients with 3 and more negative SNs it is $<10 \%$. On the other hand the goal to achieve a FNR $<10 \%$ should not lead to remove more non-SNs.

If the lymph node was marked before PST and if this target lymph node (TLN) is negative after PST, a majority of the St. Gallen panelists (92.1\%) vote for abstaining from an ALND, if additional SNs were removed and were also negative. In this situation, the AGO recommends removing the SLN(s) as well as the TLN (targeted axillary dissection, TAD). If these lymph nodes are negative, an ALND can be avoided. Various validation studies are currently being performed to demonstrate the reproducibility of the method.

The St. Gallen panelists (majority vote 63.8\%) and the German experts agree that in patients with histological proven node involvement at first diagnosis, an ALND is necessary if one out of three detected SNs has micrometastases and no radiation is planned. In this situation, there is a high risk that other lymph nodes beyond the $\mathrm{SN}$ are positive.

\section{Radiation of the lymphatic drainage areas following PST}

Most of the St. Gallen panelists (43.8\%) voted in favour of radiation of the LDA in clinically node-positive patient $(\mathrm{cN}+)$ who converted to negative SN following PST, as a standard procedure. Approximately $17 \%$ do not consider radiation of the LDA to be a standard procedure and $22.9 \%$ voted for LDA radiation only if risk factors, such as a large primary tumour, vascular infiltration, a high number of suspicious LNs at first diagnosis were present. The German expert group basically agrees with this vote. In patients with complete remission (pCR) (ypT0/is ypN0) after PST, LDA radiation can be omitted. The German experts refer to the recommendations of the AGO ( $\bullet$ Fig. 2) [2].

\section{Focus on Partial Breast and Hypofractionated Radiation}

The German expert group agrees with the simple majority vote (43.8\%) of the St. Gallen panelists that the (accelerated) partial breast irradiation (PBI) is an option for patients who are classified as suitable according to the definition of the ASTRO (American Society of Radiation-Oncology) and GEC-ESTRO (Groupe Européen de Curiethérapie-European Society for Radiotherapy \& Oncology) and who have a low risk of recurrence [7-10].

A majority of the St. Gallen panelists (52.1\%) consider the hypofractionated radiation of the breast and chest wall to be a standard procedure for fundamentally all patients in whom adjuvant subsequent radiation is indicated. The German expert group explicitly agrees with this vote for breast-conserving surgery and refers to the insufficient data with regard to hypofractionated chest wall radiation. The German experts refer to the recommendations of the AGO [2].

The vote of the St. Gallen panelists as to whether hypofractionated radiation should also apply to radiation of the LDA is less clear. Only $36.2 \%$ consider this to be a standard procedure. Just under 30\% (29.8\%) were explicitly against and just as many panelists abstained from voting. From the German standpoint as well, hypofractionated radiation of the regional lymph nodes is not a standard procedure.

\section{Radiation of the Axilla Following BCT}

After BCT, the radiation of the lymphatic drainage area should always include the non-axillary lymph nodes (supraclavicular \pm internal thoracic artery region) if at least four axillary lymph nodes are involved, according to the vote (93.8\%) of the St. Gallen panelists. If "only" 1-3 axillary lymph nodes are positive, all regional lymphatic drainage areas should be included if additional prognostically unfavourable characteristics are present, such as a triple-negative breast cancer (TNBC) or residual tumour following PST, according to the majority vote (56.2\%) of the panelists. The German expert group agrees. 
Radiation therapy after NACT

\begin{tabular}{|c|c|c|c|c|c|c|c|}
\hline \multirow[t]{2}{*}{ Pre-therapeutic } & \multirow[t]{2}{*}{ Post-therapeutic } & \multirow[t]{2}{*}{ RT-BCT } & \multirow[t]{2}{*}{ PMRT } & \multirow{2}{*}{$\begin{array}{l}\text { RT-lymphatic } \\
\text { vessels }\end{array}$} & \multicolumn{2}{|c|}{ Oxford } & \multirow[b]{2}{*}{ AGO } \\
\hline & & & & & LoE & GR & \\
\hline Locally advanced & $\mathrm{pCR} /$ no $\mathrm{pCR}$ & Yes & Yes & Yes & $1 a / 1 a / 1 a$ & $\mathrm{~A} / \mathrm{A} / \mathrm{A}$ & $++/++1++$ \\
\hline $\mathrm{cT} 1 / 2 \mathrm{cN} 1+^{*}$ & $\begin{array}{l}\text { ypT1+ or ypN1 } \\
+ \text { (no pCR) }\end{array}$ & Yes & Yes & Yes & $1 \mathrm{a} / 2 \mathrm{~b} / 2 \mathrm{~b}$ & $A / B / B$ & $++1+1+$ \\
\hline $\mathrm{cT} 1 / 2 \mathrm{cN} 1+^{*}$ & ypTO/is ypNO & Yes & \multicolumn{2}{|c|}{ Risk cases $^{1}$} & $2 b / 2 b / 2 b$ & $\mathrm{~B} / \mathrm{B} / \mathrm{B}$ & $+1+1+$ \\
\hline $\begin{array}{c}\mathrm{cT} 1 / 2 \mathrm{cN0} \\
\text { (ultrasound mandatory) }\end{array}$ & урт0/is ypNO & Yes & No & No & $2 b / 2 b / 2 b$ & $A / B / B$ & $+1-1-$ \\
\hline
\end{tabular}

\section{Locally advanced: $\mathrm{T3}-4$ or cN2-N3}

${ }^{1}$ Criteria for a high risk of recurrence:

- pN0 premenopausal high risk: central or medial site, and (G2-3 and ER/PgR-negative)

- Pretherapeutically pN1a/cN+* high risk: central or medial site and (G2-3 or ER/PgR-negative) or premenopausal, lateral site and (G2-3 or ER/PgR-negative)

* Confirmed on core biopsy

- Fig. 2 AGO recommendation 2019 on adjuvant radiation following NACT [2]. Photo credit: Courtesy of AGO

\section{Radiation Therapy Following Mastectomy}

Adjuvant radiotherapy after mastectomy includes radiation of the chest wall and the LDA. The question whether PMRT in patients with a PT3 pN0 carcinoma should be considered standard had a narrow majority of St. Gallen panelists (56.2 vs. $43.8 \%$ ). In an additional (spontaneous) vote on site, $54.3 \%$ of the panelists voted for a case-by-case decision. The German expert group refers to the AGO ( $\triangleright$ Fig. 3). This applies only to pT3pN0 patients with additional risk factors. Otherwise an individual decision should be discussed in the tumour board.

The majority of the St. Gallen panelists (63.8\%) and the German experts do not generally recommend PMRT as a standard procedure in patients with $\mathrm{pT} 2 \mathrm{pN} 0$ carcinomas with unfavourable factors.

The St. Gallen panelists did not achieve any majority vote for PMRT in patients with $1-3$ positive lymph nodes $(\mathrm{N}+1-3)$ and positive ER and/or HER2 status (ER+ and/or HER2+). However, over $85 \%$ of the St. Gallen panelists consider PMRT to be a standard procedure in patients with $\mathrm{N}+1-3$ and unfavourable characteristics (for example in the case of TNBC). The German expert group agrees with this last vote and refers to the AGO recommendations ( $>$ Fig. 4) [2].

A majority $(66.0 \%)$ of the St. Gallen panelists also consider PMRT to be a standard indication in patients with 1-2 positive SNs if the patients have not received any PST and no ALND. The German expert group points out that PMRT is generally recommended in these patients if no ALND was performed.

A clear majority of the St. Gallen panelists (75\%) and the German expert group also agree that PMRT is indicated regardless of whether or not primary breast reconstruction is performed.

\section{Postmastectomy radiation (PMRT)* of the chest wall}

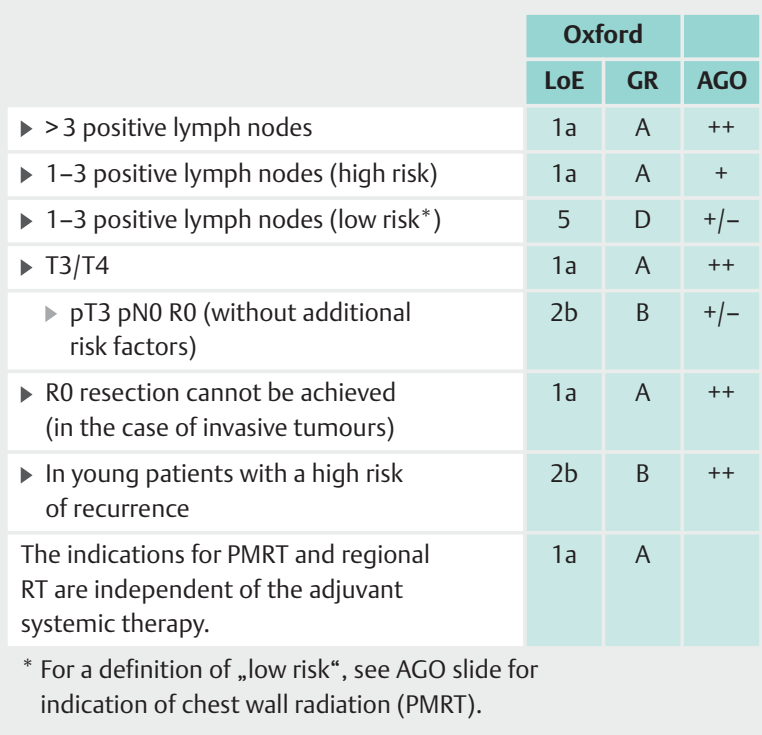

D Fig. 3 AGO recommendation 2019 on PMRT of the chest wall [2]. Photo credit: Courtesy of AGO 


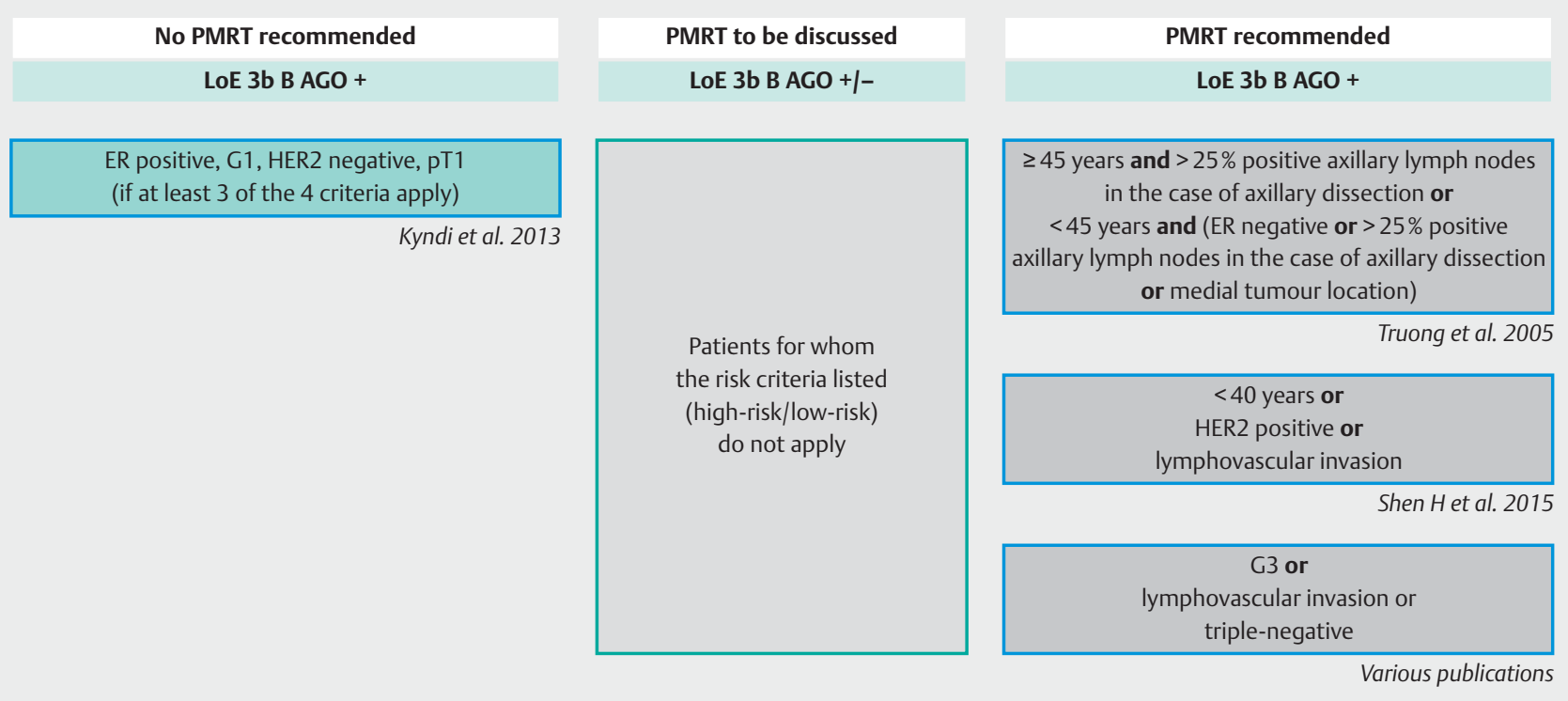

Comment: „If there is an indication for radiation of the LDA, radiation of the chest wall should also be applied.“

> Fig. 4 AGO recommendation 2019 for the indication of chest wall radiation in patients with 1-3 axillary lymph node metastases [2]. Photo credit: Courtesy of AGO

\section{Radiation Following PST - Also in the Elderly Patient}

According to the current mostly retrospective data patients without severe comorbidities with TNBC in stage T3N0 who responded well to the PST (e.g. pCR with no residual invasive and noninvasive tumour in the previous tumour bed of $6 \mathrm{~cm}$ with tumour free $\mathrm{SN}$ ) should receive PMRT since the therapeutic decision is based on the baseline risk.

Nearly $55 \%$ (54.2\%) of the St. Gallen panelists voted in favour of postoperative radiation and adjuvant endocrine therapy in a 70year-old patient without severe comorbidities (stage I, ER+) after breast-conserving surgery. $35.4 \%$ of the panelists would provide only endocrine treatment. If the same patient is older than 80 , $62.2 \%$ of the St. Gallen panelists would be more conservative with the adjuvant treatment recommendation.

The German expert group agrees with this trend that in the case of advanced age and potentially limited life expectancy, a reduced treatment may be reasonable. However, the German experts point out, as a general principle, that age per se is not a criterion for the therapeutic decision. Comorbidities and the remaining life expectancy are also important factors when reduced therapy is considered. A consultation by a radiooncologist should be nonetheless recommended in this case.

\section{Pathology: Focus on TILs and PD-L1}

The importance of tumour-infiltrating lymphocytes (TILs) for treatment decision has been discussed for many years. The German expert group does not agree with the vote of the St. Gallen panelists to routinely measure TILs in patients with TNBC. A high percentage of TILs does not imply that chemotherapy can be avoided. The German experts stress that the TIL level currently does not yield any therapeutic consequences.

In view of the IMpassion 130 study $[11,12]$ and the U. S. approval of the first PD-L1 (programmed cell death ligand 1) checkpoint inhibitor for metastatic PD-L1 positive TNBC (in combination with nab-paclitaxel), the need of determining PD-L1 expression is discussed. A majority of St. Gallen panelists (79.2\%) do not recommend to determine PD-L1 expression routinely in early TNBC. This also applies to the PD-L1 expression on immune cells (majority vote $91.5 \%$ ). The German expert group agrees with both votes.

\section{Importance of multigene signatures}

Multigene signatures may support the therapeutic decision for or against chemotherapy in patients with ER+/HER2- early breast cancer. Over $90 \%$ of the St. Gallen panelists recommend the use of multigene signatures for patients with a T1/2 tumour without lymph node involvement (93.6\%), but a majority also recommend it for those with T3N0 tumours (74.5\%) as well as independent of the T stage for patients with $1-3$ positive nodes (78.7\%). The German expert group recommend signatures only if the classical clinical parameters do not offer a sufficient basis for a therapeutic de- 


\begin{tabular}{|c|c|c|c|}
\hline \multicolumn{4}{|c|}{ Prognostic factors III - Primary breast cancer } \\
\hline Factor & $\begin{array}{l}\text { LoE } \\
2009\end{array}$ & CTS & AGO \\
\hline \multicolumn{4}{|l|}{ D Multigene assays } \\
\hline DndoPredict ${ }^{\circledR}(\mathrm{N} 0-1, \mathrm{HR}+, \mathrm{HER} 2-)$ & 1 & B & $+^{*}$ \\
\hline Drosigna ${ }^{\circledR}(\mathrm{N} 0-1, \mathrm{HR}+, \mathrm{HER} 2-)$ & 1 & B & $+*$ \\
\hline $\begin{array}{l}\text { MammaPrint }{ }^{\circledR} \text { (70 gene signature) } \\
\text { (N0-1) }\end{array}$ & I & A & $+^{*}$ \\
\hline Oncotype DX ${ }^{\circledR}(\mathrm{N} 0-1, \mathrm{HR}+, \mathrm{HER} 2-)$ & 1 & A & $+^{*}$ \\
\hline $\begin{array}{l}\text { Disseminated tumour cells } \\
\text { (DTC, in the bone marrow) }\end{array}$ & 1 & A & $+1-$ \\
\hline $\begin{array}{l}\text { Circulating tumour cells } \\
\left(\text { CTC, in the blood, Cell Search }{ }^{\circledR}\right)^{\$}\end{array}$ & 1 & A & $+1-$ \\
\hline $\begin{array}{l}\text { CTC before NACT } \\
\text { (in regard to OS, DDFS, LRFI) }\end{array}$ & $I^{*}$ & B & $+1-$ \\
\hline $\begin{array}{l}\text { Therapeutic decisions based on } \\
\text { CTC phenotypes }\end{array}$ & III & C & - \\
\hline $\begin{array}{l}\text { Cell-free DNA } \\
\text { (cfDNA, in the blood, for DFS, PFS, OS) }\end{array}$ & 1 & B & $+1-$ \\
\hline \multicolumn{4}{|c|}{$\begin{array}{l}{ }^{*} \text { Should be used only in selected patients if all other criteria } \\
\text { do not permit any therapeutic decision. }\end{array}$} \\
\hline
\end{tabular}

- Fig. 5 AGO recommendation 2019 on the use of multigene expression signatures [2]. Photo credit: Courtesy of AGO

cision for or against chemotherapy ( $\bullet$ Fig. 5) [2]. In patients with lymph node involvement, the clinical value of the multigene signatures has not been demonstrated to date in prospective studies and thus multigene signatures are not considered to be indicated here.

\section{Adjuvant Endocrine Therapy}

Adjuvant endocrine treatment is the therapy of choice for patients with ER+ (hormone-sensitive) breast cancer [2]. The ideal cut-off value for endocrine therapy is at ER $>10 \%$, according to a simple majority vote $(38.8 \%)$ of the panelists. About $25 \%$ of the panelists think that the cut-off is not clearly defined and $30.1 \%$ considered the cut-off to be at ER > $1 \%$.

The vote makes it clear that there is no ideal cut-off value. From the German standpoint, there is formally an indication for endocrine therapy starting at an ER value of $\geq 1 \%$. The therapeutic decision in this situation should be discussed in the tumour board and with the patient under consideration of other prognostic factors.

\section{Selection factors in premenopause}

For premenopausal patients with an early ER+ breast cancer, ovarian function suppression (OFS: GnRH analogues or bilateral ovariectomy) in addition to tamoxifen or an aromatase inhibitor (AI) is an option. Two thirds (68.1\%) of the St. Gallen panelists believe that additional OFS is indicated whenever there is an indication for chemotherapy in the setting of a high risk of recurrence. The German expert group agrees.

Other clinical-pathological factors which justify an OFS indication by itself, thus without other factors needing to be present, include, in a majority of the panelists' opinions (84.8\%) young patients $\leq 35$ years of age, and $59.6 \%$ of the panelists think this also applies in case of a higher risk result of a multigene expression analysis. The German expert group does not agree with the two votes: A young age per se is not an indication for OFS. There are no data on multigene expression analyses and their impact with regard to an escalation of endocrine therapy.

There is agreement that neither a moderate risk without an indication for chemotherapy nor a positive HER2 status justify an indication for OFS. From the German viewpoint, this also applies to lymph node involvement. The essential prerequisite for the indication for OFS is the persistent ovarian function following (neo)adjuvant chemotherapy as well as the risk of recurrence. This is always the case with at least 4 positive lymph nodes and in the case of 1-3 positive nodes with regard to other risk factors. The German experts do not agree with a simple majority (37.8\%) of the St. Gallen panelists that a positive node (per se) justifies an OFS indication.

The St. Gallen panelists (55.1\%) and the German expert group agree that duration of OFS treatment should be for five years if there is an indication [13]. If an $\mathrm{Al}$ is administered, the additional OFS is obligatory in the premenopausal patient. With tamoxifen, OFS can be stopped early if this is necessary, for example, due to adverse effects.

\section{Endocrine therapy in postmenopause}

Postmenopausal patients with ER+ early breast cancer should receive an $\mathrm{Al}$ at some point in the course of therapy. The German expert group agrees with the majority vote (95.7\%) of the panelists. G3, a high Ki-67 value or a positive HER2 status are indications for an Al. The German expert group agrees with the majority vote of the panelists, however it refers to the fact that the factors listed are not predictive factors for the benefit of an Al administration. They rather imply an increased risk of recurrence. There is agreement that Al does not necessarily need to be used from the very beginning (“upfront”). However, an upfront administration of the $\mathrm{Al}$ is recommended in the case of increased risk due to an advanced tumour stage.

\section{Therapy of the premenopausal patient after five years of tamoxifen}

In breast cancer patients in stage I who are still premenopausal after five years of tamoxifen therapy, the treatment should be stopped, according to a simple majority vote of the panelists (54.3\%). $37.0 \%$ of the panelists voted in favour of further treatment with tamoxifen for another five years. The German expert group agrees with the majority vote (therapy stop), however it points out that in this situation, individual case-by-case decisions are possible, based on the patient's need.

Premenopausal patients who are in stage II following initial diagnosis and who have positive lymph nodes should receive tamoxifen for another five years - thus for a total of ten years (79.6\%). None of the panelists voted in favour of ending therapy 
in this situation with an increased baseline risk. The German expert group agrees.

\section{Extended endocrine therapy in postmenopause}

Endocrine therapy for more than five years requires that the treatment is adequately tolerated in the first five years. Under this premise, the so-called extended endocrine therapy for patients with ER+ breast cancer in stage II can be an option. A majority of panelists recommended extended endocrine therapy in the following situations:

- Patients in stage II who were treated in the first five years with tamoxifen - independent of lymph node involvement at first diagnosis (N0: 68.1\%, N+: 97.9\%).

- Patients in stage II with lymph node involvement at first diagnosis who were treated for five years with an $\mathrm{Al}$ (81.2\%).

The majority of the panelists see no indication for extended endocrine therapy for these patients:

- Patients in stage I - independent of which previous endocrine therapy (tamoxifen or $\mathrm{Al}$ ) was used.

- Patients in stage II if there was no lymph node involvement at first diagnosis and the patients had an Al for five years.

The German expert group agrees with the results of the voting in each case, however refers to the fact that the extended endocrine therapy can also be an option in patients with a presumed low risk (stage I and stage II [N0, Al upfront therapy for 5 years]) in the individual case - depending on the risk-benefit assessment and the patient's preference and following a detailed explanation.

Approximately $60 \%$ of the panelists voted in favour of extended endocrine therapy for five years, corresponding to a total therapy period of ten years; just around one-third (31.7\%) voted in favour of a total therapy period of 7-8 years. From the German standpoint, the duration of therapy depends on the previous endocrine therapy and should be differentiated accordingly: A total therapy period of ten years is, from the German standpoint, an option for patients with five years of tamoxifen pretreatment. If patients already had an $\mathrm{Al}$ in the first five years, the extended endocrine treatment is preferably continued over $2-3$ years, corresponding to a total therapy period of 7-8 years. However, for patients with a particularly high risk of recurrence (e.g. $\geq 10$ positive lymph nodes, G3 etc.), extended endocrine therapy for more than ten years is an option.

\section{Chemotherapy indication in low-risk carcinoma?}

According to the majority of the St. Gallen panelists (64.6\%), adjuvant chemotherapy is indicated if 4-9 lymph nodes are positive at first diagnosis. This also applies in the case of luminal $A$ breast cancer (ER+/HER2-, G1) as well as in the case of "classic" lobular breast cancer. The German expert group agrees.

\section{Importance of Multigene Expression Analyses}

This year, the St. Gallen panelists no longer voted on individual multigene signatures. A portion of the votes related to the prospective studies, such as the TAILORx [14] or the MINDACT study [15]. The German expert group points out that, according to the recommendation of the $\mathrm{AGO}$, each of the four available multigene signatures - OncotypeDX ${ }^{\circledR}$ Recurrence Score (RS), MammaPrint $70^{\circledR}$ (MP), Prosigna ${ }^{\circledR}$ PAM 50 Risk of Recurrence Score (ROR), EndoPredict $^{\circledR}(\mathrm{EP})$ - can be used if there is an indication ( $\bullet$ Fig. 5) [2].

\section{Patients without lymph node involvement}

According to the TAILORx study [14], patients without lymph node involvement and a recurrence score (RS) of $\leq 25$ do not need chemotherapy. In premenopausal patients ( $<50$ years) with an RS of $21-25$, a slight majority $(52.1 \%)$ of the panelists see an indication for chemotherapy in addition to endocrine therapy \pm OFS. $10.4 \%$ of the panelists voted in favour of the additional OFS. One-fourth of the panelists see an indication for additional OFS, however not for chemotherapy.

The German expert group confirms the chemotherapy indication in these patients. If the patient is premenopausal after chemotherapy, OFS should be recommended in addition to endocrine therapy. If there is a clearly postmenopausal situation, endocrine therapy without OFS should be recommended following chemotherapy.

$57.1 \%$ of the panelists think that a postmenopausal patient without lymph node involvement and an RS of $\geq 26$ should receive chemotherapy depends on other histopathological criteria as well as the patient's preferences. $38.8 \%$ of the panelists agreed with routine use of chemotherapy in this situation. The German expert group agrees with the majority vote that histopathological criteria should be taken into account when making a therapeutic decision.

\section{Patients with lymph node involvement}

In the Plan B [16] and MINDACT study [15], the RS and the MP (MammaPrint) were also validated in the case of patients with lymph node involvement. In view of the Plan B study, a majority (78.7\%) of the panelists did not feel that adjuvant chemotherapy was indicated in patients with an RS of $<11$ or in patients $>50$ years and 1-2 positive lymph nodes. The German expert group notes: Since pre- and postmenopausal patients were randomised in the Plan B study, a decision based on age is difficult. Whether adjuvant chemotherapy can be avoided in younger patients ( $<50$ years) with $1-2$ positive lymph nodes and low RS (RS $<11$ ) was the subject of controversial discussion in the German expert panel. Half were in favour and the other half were against omitting adjuvant chemotherapy in these patients.

There is no indication for adjuvant chemotherapy in view of the MINDACT study [15] in patients with a low risk (MP score) and 1-2 positive lymph nodes. Here the panelists and the German expert group were in agreement that this applies, independent of age, to patients <50 years (majority vote: $78.7 \%$ ) and also to those 


\section{Subtype-specific strategies for systemic therapy}

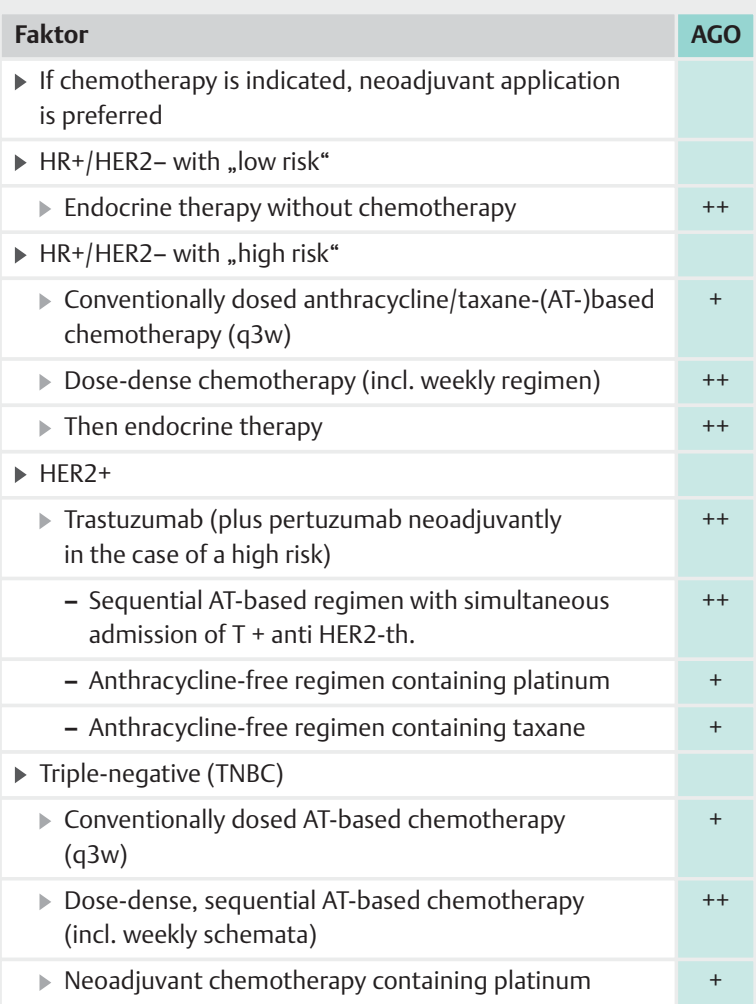

- Fig. 6 AGO recommendation 2019 on subgroup-specific systemic therapy in the case of early breast cancer [2]. Photo credit: Courtesy of AGO

$>50$ years (majority vote: $80.9 \%$ ). The German expert group also refers to the recommendation of the AGO [2], according to which no differentiation is made in Germany between the available, clinically validated multigene signatures ( $\triangleright$ Fig. 5 ).

\section{Neoadjuvant endocrine therapy?}

For postmenopausal patients, neoadjuvant endocrine therapy should be preferred over neoadjuvant chemotherapy if a luminal A-like subtype is present which was confirmed on immunohistochemistry or by means of multigene expression analysis and for which endocrine therapy is suggested. This is the majority vote of the panelists (81.2\%) which is in line with that of the German expert group. There is also agreement that neoadjuvant endocrine therapy should be performed until an optimal reduction in the tumour load is reached, generally at least six months.

\section{Adjuvant and Neoadjuvant Chemotherapy}

\section{Chemotherapy in ER+/N0 patients}

Patients with an ER+ breast cancer without lymph node involvement (N0) should preferably receive chemotherapy with a taxane plus an alkylating agent if chemotherapy is indicated, according to the majority vote of the panelists (54.2\%) This does not correspond to the AGO recommendation [2]. In Germany, anthracycline-/ taxane-based regimens plus an alkylating agent are preferred. In individual cases an anthracycline-free regimen can be used, such as the combination of docetaxel/cyclophosphamide (TC).

\section{Chemotherapy in TNBC}

In patients with TNBC, the majority of the St. Gallen panelists prefer anthracycline-/taxane-based regimens plus an alkylating agent starting at stage I (stage I: $77.6 \%$ : stage II or III: $93.3 \%$ ), which is in line with the AGO [2]. However, in pT1a/b TNBC, a majority of the panelists (52.2\%) would not recommend an anthracycline. According to the recommendation of the AGO, an alkylatingagent-/taxane-based regimen \pm anthracycline is an evidencebased option [2]. The German experts add that in patients with TNBC, the neoadjuvant use of chemotherapy should be preferred. This is based on the prognostically importance of the response and the possibility to use postneoadjuvant therapy in case of non-pCR. Anthracycline-/taxane-based regimens should preferably be used in a dose-dense manner in the (neo)adjuvant setting, according to the majority vote of the panelists (61.0\%) which is in line with that of the German expert group (

\section{Neoadjuvant use of platinum?}

The neoadjuvant use of platinum in TNBC has been debated many times. A higher pCR rate is reached with neoadjuvant chemotherapy containing platinum [17-20]. In the GeparSixto study, the higher $\mathrm{PCR}$ rate translated into a longer DFS for all TNBC patients - independent of BRCA1/2 status $(p<0.001)$ [19]. The AGO recommends the neoadjuvant use of platinum in the case of an increased risk (high tumour load, poor response to first two cycles of chemotherapy) ( $\bullet$ Fig. 6). The German expert group therefore does not agree with the St. Gallen panelists, a majority of whom (56.5\%) rejected the neoadjuvant use of platinum in addition to an anthracycline-/alkylating agent-/taxane-based regimen.

Likewise the German expert group does not agree with the majority vote of the panelists (67.3\%) to limit the neoadjuvant use of platinum to patients with a BRCA mutation. The BRCA mutation is not a predictor for the use of platinum. The BRCA mutation increases the chemotherapy sensitivity of the tumour, however not in particular the sensitivity to platinum [19].

\section{Chemotherapy in patients with small TNBC (pT1apN0)?}

Even in a patient with a small, unifocal TNBC without lymph node involvement ( $<6 \mathrm{~mm}, \mathrm{~N} 0$ ), chemotherapy may be indicated, according to the majority vote $(65.3 \%$ ) of the panelists. The German expert group considers this to be an individual, case-by-case decision: An indication for chemotherapy may be an option in this situation primarily for young patients, in the case of a highly proliferative carcinoma, or for patients preference.

\section{Focus on HER2+ Breast Cancer}

A high level of agreement between the panelists and the German expert group is seen in the voting results on anti-HER2-targeted treatment in HER2+ early breast cancer: 
- Patients with HER2-positive (HER2+) breast cancer receive anti-HER2-targeted therapy in addition to chemotherapy. This applies starting at stage I [2], however this is not a standard in T1a carcinomas without lymph node involvement (N0) (majority vote (55.3\%).

- In stage I, the additional use of trastuzumab to chemotherapy is independent of the ER status standard (majority vote: $61.7 \%$ ). The preferred adjuvant regimen is the combination of taxane/trastuzumab (majority vote: $73.5 \%$ ).

- If neoadjuvant trastuzumab is indicated in HER2+/ER+ breast cancer in stage I, this does not imply that the additional use of pertuzumab is standard (majority vote: $52.1 \%, 14.6 \%$ abstentions).

- According to the marketing authorisation, pertuzumab is indicated in patients with lymph node involvement $(\mathrm{N}+)$ and/or in the case of negative ER status (ER-) and this is also recommended by the AGO [2]. The majority vote (48.9\%) of the St. Gallen panelists who see no indication for double antibody blockade with pertuzumab in stage I of HER2+ breast cancer is in contrast with the AGO recommendation [2].

- Patients in stage // with lymph node involvement $(\mathrm{N}+)$ or those in stage III should preferably receive neoadjuvant combination therapy with AC (doxorubicin/cyclophosphamide) or EC (epirubicin/cyclophosphamide) followed by taxane plus double antibody blockade (trastuzumab/pertuzumab) (majority vote: $75.5 \%)$.

- According to the majority vote (76.6\%), the dual antibody blockade with trastuzumab/pertuzumab is the preferred therapeutic option for all patients in stage II $(\mathrm{N}+)$ or in stage III.

- If trastuzumab is indicated, the duration of therapy is twelve months (majority vote: $89.8 \%$ ).

\section{Use of neratinib}

Following the (neo)adjuvant administration of trastuzumab, the adjuvant use of neratinib is a therapeutic option for patients with HER+ breast cancer. However, in the approval study ExteNET [21] a very selected patient group benefited from neratinib - those with HER2+/ER+ breast cancer and at least four positive lymph nodes. Because of considerable toxicity, the adjuvant use of neratinib is viewed critically. The voting result of the St. Gallen panelists revealed support for neratinib in all node-positive patients with $\mathrm{HR}+/ \mathrm{HER} 2+$ breast cancer by $21 \%$ of the panelists and in the case of four or more positive lymph nodes by $27 \%$, and abstentions by $29.2 \%$.

The German expert group agrees with this vote, however refers to the considerable toxicity (diarrhoea). In the current AGO guidelines, neratinib received a plus/minus recommendation based on the ExteNET study [21] and is thus an option for individual patients [2]. There are no data for the adjuvant use of neratinib following dual antibody blockade.

\section{Residual tumour after neoadjuvant systemic therapy}

The St. Gallen panelists and the German expert group agree that neoadjuvant systemic therapy is the preferred treatment for patients with TNBC and HER2+ breast cancer in stage II/III - independent of whether or not breast-conserving surgery can be performed (majority vote: $98.0 \%$ ). The crucial advantage of the neo- adjuvant therapy is the assessment of the response and the possibilty to add postneoadjuvant treatment in non-pCR patients [2].

If residual tumour remains in the breast and or in the lymph nodes of patients with TNBC following neoadjuvant sequential therapy with AC taxane, the German expert group agrees with the majority vote of the St. Gallen panelists to treat these patients with capecitabine after surgery $[22,23]$. This recommendation applies independent of the size of the residual tumour $(\geq \mid<1 \mathrm{~cm})$ and the lymph node involvement $(\mathrm{N}+\mathrm{N} 0)$.

For patients with HER2+ breast cancer and residual tumour in the breast and/or axilla following neoadjuvant systemic therapy, the postneoadjuvant use of T-DM1 is a new option [24]. Over $90 \%$ of the St. Gallen panelists and the German expert group agree. The size of the residual tumour and the tumour load in the axilla is not relevant for the use of T-DM1. Also irrelevant is whether patients received neoadjuvant trastuzumab or the dual antibody blockade with trastuzumab/pertuzumab in addition to chemotherapy.

\section{pCR after neoadjuvant systemic therapy}

A discussion point is the adjuvant continuation of treatment of patients with HER2+ breast cancer and pCR after neoadjuvant therapy. If patients with lymph node involvement at first diagnosis achieve pCR after neoadjuvant polychemotherapy and dual antibody blockade (trastuzumab/pertuzumab), a simple majority $(47.7 \%)$ of the St. Gallen panelists prefers to continue treatment with both antibodies in the adjuvant setting; $38.6 \%$ would use trastuzumab alone in the adjuvant setting. The German expert group agrees with the majority vote. According to the German experts, this is indeed not proven by studies, but the tumour biology is used as a rationale. This does not change after $\mathrm{PCR}$, therefore an elevated risk might remain which justifies the use of both antibodies.

From the German standpoint, this also applies to patients without lymph node involvement ( $\mathrm{CNO}$ ) at initial diagnosis if both antibodies were used in addition to the neoadjuvant polychemotherapy (according to authorisation in the case of HER2+/ER-). In this case, a majority of the St. Gallen panelists (52.2\%) voted in favour of adjuvant treatment with trastuzumab. From the German standpoint, treatment should not be de-escalated if there is an increased baseline risk (e.g. ER-).

\section{Adjuvant "Bone-Modifying" Therapy}

The additional adjuvant use of a bisphosphonate (zoledronic acid every six months or oral clodronate daily) to adjuvant endocrine therapy can prolong the disease-free survival (DFS) and improve overall survival in postmenopausal patients. This applies independent of the bone density. However, in a meta-analysis [25] on the adjuvant use of bisphosphonates, only patients with lymph node involvement benefited from bisphosphonate therapy. The Austrian ABCSG 12 study [26] shows that this also applies for premenopausal patients if they additionally received a $\mathrm{GnRH}$ analogue during adjuvant endocrine therapy.

In view of these data, a slight majority (53.1\%) of the panelists were in favour of additionally recommending a bisphosphonate (zoledronic acid or clodronate) to prolong DFS independent of 
Ovarian dysfunction prophylaxis and preservation of fertility in premenopausal patients with (neo-)adjuvant chemotherapy (CT)

\begin{tabular}{|c|c|c|c|}
\hline & \multicolumn{2}{|c|}{ Oxford } & \multirow[b]{2}{*}{ AGO } \\
\hline & LoE & GR & \\
\hline $\begin{array}{l}\text { CHT + GnRHa } \\
\text { (for ovarian dysfunction prophylaxis) } \\
\text { (GnRHa application > } 2 \text { weeks } \\
\text { prior to chemotherapy, independent } \\
\text { of hormone receptor status) }\end{array}$ & $1 a$ & A & + \\
\hline $\begin{array}{l}\text { CHT }+\mathrm{GnRHa} \\
\text { (to increase the rate of pregnancy) }\end{array}$ & $1 b$ & A & $+1-$ \\
\hline $\begin{array}{l}\text { Offer for counselling regarding } \\
\text { preservation of fertility, } \\
\text { incl. assisted reproductive therapy }\end{array}$ & & & ++ \\
\hline
\end{tabular}

- Fig. 7 AGO recommendation 2019 on fertility protection on (neo)adjuvant chemotherapy [2]. Photo credit: Courtesy of AGO

bone density in premenopausal patients who adjuvantly received a GnRH analogue plus tamoxifen or Al.

The German expert group did not reach agreement regarding this question. Critics argue that the indication for a bisphosphonate to prolong DFS in premenopausal patients is based only on one study (ABCSG-12) [26]. The AGO correspondingly issued a "plus/minus" recommendation (individual, case-by-case decision) [2]. There is agreement that the osteoprotective effect of bisphosphonates can be seen independent of the indication of prolongation of DFS.

In the case of postmenopausal patients, the German experts agreed with the St. Gallen panelists (83.7\%) that a bisphosphonate can be used for prolonging DFS. Interestingly, however, only $42.6 \%$ of the panelists indicated in an additional vote that they implemented this in their own clinical practice. No indication for DFS prolongation exists because of the controversial data with the adjuvant use of denosumab ( $60 \mathrm{mg}$, every 6 months). The German expert group agrees with the majority vote (75\%) of the panelists. The approval study (D-CARE) [27] was not able to demonstrate any improvement in DFS with denosumab, in contrast to the ABCSG-18 study $[28,29]$. However, a positive effect on the fracture rate was seen in the D-Care study [27].

\section{Preservation of Fertility}

Preservation of fertility on (neo)adjuvant chemotherapy by means of ovarian function suppression should be offered to all patients wanting a child, independent of the hormone receptor (HR) status of the tumour [2]. The German expert group agrees with the majority vote of the panelists for patients with HR-negative (91.5\%) and also HR-positive tumours (79.6\%) and adds that this applies to all patients of childbearing age. For more information, the German experts refer to the AGO recommendation ( $\bullet$ Fig. 7) and the initiative FertiPROTEKT (www.fertiprotekt.de).

\section{Genetic Testing for High-Risk Mutations?}

Genetic testing for high-risk mutations (e.g. BRCA1/2 testing) calls for appropriate patient information and counselling. The German expert group agrees with the majority vote $(70.8 \%)$ of the St. Gallen panelists that such testing should not be considered for all patients - independent of the family risk. The panelists voted unanimously $(100 \% !)$ to recommend genetic testing to women from high-risk families (significantly positive family history). The panelists voted nearly unanimously (95.9\%) for genetic testing in patients who are younger than 35 years of age at the time of diagnosis.

There is agreement than an age cut-off value of below age 50 is not suitable for recommending genetic testing without a family history. Therefore there is no general indication for testing in patients under age 50 . The situation is different in the case of patients with TNBC. Here, the St. Gallen panelists $(85.4 \%)$ and the German experts recommend genetic testing if the patient is under 60 years of age at first diagnosis.

\section{Pregnancy After Breast Cancer}

Breast cancer patients who wish to have a child should be actively counselled. The endocrine treatment can be interrupted if the patient wishes to have a child and if there is no high-risk situation. This should be done after 18 months at the earliest (78.0\%). The German expert group therefore agrees with the majority vote (79.2\%) of the panelists to not interrupt therapy at any given moment. Since the benefit of adjuvant endocrine therapy correlates with the duration of therapy, the German experts favour endocrine therapy lasting at least 24 months before pregnancy occurs.

Just under $60 \%$ (59.6\%) of the St. Gallen panelists recommend that the patient undergo a re-staging prior to pregnancy. The German expert group also considers a re-staging to be advisable and adds that the decision to have a child is an individual decision of the patient. The counseling physician should provide the patient with information as well as constructive and empathetic support.

\section{Nutrition and Exercise}

There is agreement that patients should be made aware of the overall prognostic importance of a healthy lifestyle with, for example, a varied (healthy) diet and appropriate physical activity with the objective of avoiding significant overweight.

\section{Ductal Carcinoma in situ (DCIS)}

The voting questions presented within the framework of the St. Gallen consensus meeting on the treatment of DCIS did not adequately reflect the complexity of the situation. In view of this, the German expert group agrees with the St. Gallen panelists $(97.9 \%)$ that patients with a small DCIS have a more favourable prognosis and require less intensive treatment. This applies in particular if the DCIS is discovered during screening, the patient is $\geq 50$ years of age, and the DCIS has a favourable biology.

If there are favourable prognostic factors and a clear margin ( $\geq 5 \mathrm{~mm}$ ), adjuvant radiation of the DCIS can be omitted, accord- 
ing to a vote by the panelists (84.4\%). The question of whether adjuvant endocrine treatment can be omitted was supported by a slight majority (55.6\%) of the panelists for all DCIS patients and $42.2 \%$ only for DCIS patients with favourable prognostic factors. In the case of favourable prognostic factors, $66.7 \%$ of the panelists would abstain from adjuvant radiation as well as from adjuvant endocrine therapy.

The German expert group adds that the use of tamoxifen is above all a preventive intervention with the objective of preventing an ipsi- or contralateral secondary carcinoma. The decision to treat a patient with DCIS postoperatively calls for an individual benefit/risk assessment and is based on many factors, such as the size of the tumour or the age of the patient. To date, no survival advantage has been described for DCIS patients either through endocrine therapy or radiation therapy. The margin of $\geq 5 \mathrm{~mm}$ in the voting questions is arbitrary from a German viewpoint, since no margin is presently defined in the case of DCIS.

\section{Magnitude of Absolute Benefit}

With regard to the motto of this year's consensus conference: Over $90 \%$ of the panelists agreed that more comprehensive information for a breast cancer patient includes informing her about the chances and limitations of the specific therapeutic options. In the case of therapeutic options with only very limited chances of success, this should be communicated honestly and the option of abstaining from the treatment should be discussed. The German expert group agrees.

\section{Comment}

The post St. Gallen meeting was organised and conducted by Aurikamed Institute $\mathrm{GmbH}$ and made possible by an unrestricted-content grant from Celgene $\mathrm{GmbH}$. The authors of the writing committee exclusively were responsible for preparing the manuscript. The authors thank Ms. Birgit-Kristin Pohlmann, Nordkirchen, for editorial support in drafting the manuscript.

\section{Conflict of Interest}

Prof. Michael Untch: Honoraria to the employer (for AdBoard participation, lectures) as well as travel support from Amgen, AstraZeneca, BMS, Celgene, Daiichi Sankyo, Eisai, Janssen Cilag, Johnson \& Johnson, Lilly Deutschland, Lilly International, MSD, Mundipharma, Myriad Genetics, Odonate, Pfizer, Puma Biotechnology, Riemser, Roche, Sanofi Aventis, Sividon Diagnostics, TEVA Pharmaceuticals Ind. Ltd. Prof. Christoph Thomssen received honoraria from AstraZeneca, Celgene, Genomic Health, Novartis, NanoString, Pfizer, Roche and research support from NanoString.

Dr. med. Ingo Bauerfeind has no conflict of interest.

Prof. Michael Braun received honoraria from AstraZeneca, Celgene, Daiichi Sankyo, Genomic Health, Eisai, Genomic Health, GlaxoSmithKline, Medac, Novartis, Pfizer, PumaBiotechnology, Roche, Teva.
Prof. Sara Brucker received honoraria from Novartis, Pfizer, AstraZeneca, Roche and research support from Genomic Health.

Prof. Ricardo Felberbaum has no conflict of interest. Dr. med. Friederike Hagemann has no conflict of interest. Renate Haidinger has no conflict of interest. Prof. Arnd Hönig received honoraria from Amgen, Astra Zeneca, Celgene, MSD, Pfizer, Roche, Novartis, as well as research support from Roche and Genentech and travel grants from Roche, AstraZeneca, Daiichi Sankyo, Pfizer.

Prof. Jens Huober received honoraria from Celgene, Roche, Novartis, Hexal, Pfizer, AstraZeneca, Lilly, Amgen, Eisai as well as research support from Celgene, Hexal, Novartis and travel grant from Roche, Novartis and Celgene.

Prof. Christian Jackisch received honoraria from Celgene, Novartis, Pfizer, AstraZeneca, Roche and research support from Genomic Health. Prof. Thorsten Kühn has no conflict of interest.

PD Dr. Hans-Christian Kolberg received honoraria from Pfizer, Novartis, Roche, Genomic Health, Amgen, AstraZeneca, Riemser, Carl Zeiss Meditec, TEVA, Theraclion, Janssen-Cilag, GSK, LIV Pharma as well as honoraria for consultancy work from Pfizer, Novartis, SurgVision, Carl Zeiss Meditec, Amgen, Onkowissen and owns shares of Theraclion SA, Phaon Scientific GmbH. Travel grant from Carl Zeiss Meditec, LIV Pharam, Novartis, Amgen, Pfizer and Daiichi Sankyo.

Prof. Cornelia Kolberg-Liedtke received honoraria from Roche, AstraZeneca, Celgene, Novartis, Pfizer, Lilly, Hexal, Amgen, Eisai, SonoScape as well as honoraria for consultancy work from Phaon Scientific, Novartis, Pfizer, Celgene as well as research support from Roche, Novartis, Pfizer. Travel grant from Novartis and Roche. Prof. Diana Lüftner received honoraria from AstraZeneca, Celgene, Pfizer, Novartis, Amgen, Roche, Loreal, Teva, Tesaro and Eli Lilly. Prof. Nicolai Maass received honoraria from Amgen, AstraZeneca, Celgene, Lilly, MSD, Pfizer, Roche, Novartis, Daiichi Sankyo.

Prof. Toralf Reimer received honoraria from Novartis, Pfizer, Lilly, Celgene and AstraZeneca.

Prof. Andreas Schneeweiss received honoraria from Celgene, Roche, Pfizer, AstraZeneca, Novartis, MSD, Tesaro, Lilly as well as research support from Celgene, Roche, AbbVie, Molecular Partner as well as travel grants from Celgene, Roche and Pfizer.

Eva Schumacher-Wulff has no conflict of interest.

Prof. Florian Schütz received honoraria for lectures and consultations from Amgen, AstraZeneca, ClinSol, MSD, Novartis, Pfizer, Riemser, Roche as well as a travel grant from AstraZeneca, Pfizer and Roche. PD Dr. Marc Thill received honoraria from Amgen, AstraZeneca, Aurikamed, Biom'Up, Celgene, Daiichi Sankyo, Eisai, Genomic Health, Hexal, Lilly, MCl, Medtronic, MSD, Myriad, Neodynamics, Norgine, Novartis, OnkoLive, OmniaMed, pfm Medical, Pfizer, Roche, Tesaro, Teva, RTI Surgical, and research support from Genomic Health. Dr. med. Rachel Wuerstlein received honoraria from Agendia, Amgen, AstraZeneca, Boehringer Ingelheim, Carl Zeiss, Celgene, Daiichi-Sankyo, Esai, Genomic Health, GSK, Lilly, MSD, Mundipharma, Nanostring, Novartis, Odonate, Paxman, Palleos, Pfizer, Pierre Fabre, PumaBiotechnology, Riemser, Roche, Sandoz/Hexal, Seattle Genetics, Tesaro Bio, Teva.

Prof. Peter A. Fasching reports grants from Novartis, Cepheid and Biontech as well as personal contributions from Novartis, Roche, Pfizer, Celgene, Daiichi-Sankyo, Teva, AstraZeneca, MSD, Myelo Therapeutics, Macrogenics, Eisai and Puma.

Prof. Nadia Harbeck received honoraria from Agendia, Amgen, Celgene, Genomic Health, Lilly, MSD, Nanostring, Novartis, Pfizer, Roche, Sandoz. 


\section{References}

[1] Kolberg H-C, Schneeweiss A, Fehm TN et al. Update Breast Cancer 2019 Part 3 - Current Developments in Early Breast Cancer: Review and Critical Assessment by an International Expert Panel. Geburtsh Frauenheilk 2019; 79: 470-482

[2] Ditsch N, Untch M, Thill M et al. AGO Recommendations for the Diagnosis and Treatment of Patients with Early Breast Cancer: Update 2019. Breast Care 2019; 14: im Druck. Online: www.ago-online.de; last access: 25.05.2019

[3] Reimer T, Stachs A, Nekljudova V et al. Restricted Axillary Staging in Clinically and Sonographically Node-Negative Early Invasive Breast Cancer (c/iT1-1) in the Context of Breast Conserving Therapy: First Results Following Commencement of the Intergroup-Sentinel-Mamma (INSEMA) Trial. Geburtsh Frauenheilk 2017; 77: 149-157

[4] Gentilini O, Veronesi U. Abandoning sentinel lymph node biopsy in early breast cancer? A new trial in progress at the European Institute of Oncology of Milan (SOUND: Sentinel node vs Observation after axillary UltraSouND). Breast 2012; 21: 678-681

[5] Giuliano AE, Ballman KV, McCall L et al. Effect of Axillary Dissection vs. No Axillary Dissection on 10-Year Overall Survival Among Women With Invasive Breast Cancer and Sentinel Node Metastasis: The ACOSOG Z0011 (Alliance) Randomized Clinical Trial. JAMA 2017; 318: 918-926

[6] Donker M, van Tienhoven G, Straver ME et al. Radiotherapy or surgery of the axilla after a positive sentinel node in breast cancer (EORTC 1098122023 AMAROS): a randomised, multicentre, open-label, phase 3 noninferiority trial. Lancet Oncol 2014; 15: 1303-1310

[7] Online: www.astro.org; last access: 27.03.2019

[8] Smith BD, Arthur DW, Buchholz TA et al. Consensus Statement der ASTRO. Int J Rad Oncol Bio Phys 2009; 74: 987-1001

[9] Online: www.estro.org; last access: 27.03.2019

[10] Polgàr C, Van Limbergen E, Pötter R et al. Patient selection for accelerated partial-breast irradiation (APBI) after breast-conserving surgery: recommendations of the Groupe Européen de Curiethérapie-European Society for Therapeutic Radiology and Oncology (GEC-ESTRO) breast cancer working group based on clinical evidence (2009). Radiother Oncol 2010; 94: 264-273

[11] Schmid P, Adams S, Rugo HS et al. Atezolizumab and Nab-Paclitaxel in Advanced Triple-Negative Breast Cancer. N Engl J Med 2018. doi:10.1056/NEJMoa1809615

[12] Emens LA, Loi S, Rugo HS et al. Impassion130: Efficacy in immune biomarker subgroups from the global, randomized, double-blind, placebocontrolled, Phase III study of Atezolizumab + nab-paclitaxel in patients with treatment-naïve, locally advanced or metastatic triple-negative breast cancer. SABCS 2018; abstract/oral presentation GS1-04

[13] Pagani O, Regan MM, Francis PA; TEXT and SOFT Investigators; International Breast Cancer Study Group. Exemestane with ovarian suppression in premenopausal breast cancer. N Engl J Med 2014; 371: 1358-1359

[14] Sparano JA, Gray RJ, Makower DF et al. Prospective Validation of 21-Gene Expression Assay in Breast Cancer. N Engl J Med 2015; 373: 2005-2014
[15] Cardoso F, van't Veer L], Bogaerts ] et al. 70-Gene Signature as an Aid to Treatment Decisions in Early-Stage Breast Cancer. N Engl J Med 2016; 375: 717-729

[16] Gluz O, Nitz UA, Christgen M et al. West German Study Group Phase III Plan B Trial: First Prospective Outcome Data for the 21-Gene Recurrence Score Assay and Concordance of Prognostic markers by Central and Local Pathology Assessment. J Clin Oncol 2016; 24: 2341-2349

[17] Loibl S, O'Shaughnessy J, Untch M et al. Addition of the PARP inhibitor veliparib plus carboplatin or carboplatin alone to standard neoadjuvant chemotherapy in triple-negative breast cancer (BrighTNess). A randomised, phase 3 trial. Lancet Oncol 2018; 19: 497-509

[18] Sparano JA, Zhao F, Martino S et al. Long-Term Follow-Up of the E1199 Phase III Trial Evaluating the Role of Taxane and Schedule in Operable Breast Cancer. J Clin Oncol 2015; 33: 2353-2360

[19] Hahnen E, Lederer B, Hauke J et al. Germline Mutation Status, Pathological Complete Response, and Disease-free Survival in Triple-Negative Breast Cancer: Secondary Analysis of the GeparSixto Randomized Clinical Trial. JAMA Oncol 2017; 3: 1378-1385

[20] Petrelli $F$. The value of platinum agents as neoadjuvant chemotherapy in triple-negative breast cancers: a systematic review and meta-analysis. Breast Cancer Res Treat 2014; 144: 223

[21] Martin M, Holmes FA, Ejlertsen B et al. Neratinib after trastuzumabbased adjuvant therapy in HER2-positive breast cancer (ExteNET): 5-year analysis of a randomised, double-blind, placebo-controlled, phase 3 trial. Lancet Oncol 2017. doi:10.1016/S1470-2045(17)30717-9

[22] Masuda N, Lee S-J, Ohtani S et al. Adjuvant Capecitabine for Breast Cancer after Preoperative Chemotherapy. N Engl J Med 2017; 376: 21472156

[23] Zujewski JA, Rubinstein L. CREATE-X a role for capecitabine in early-stage breast cancer: an analysis of available data. NPJ Breast Cancer 2017; 3: 27

[24] von Minckwitz G, Huang CS, Mano MS et al. Trastuzumab Emtansine for Residual Invasive HER2-Positive Breast Cancer. N Engl J Med 2018. doi:10.1056/NEJMoa1814017

[25] Early Breast Cancer Trialists' Collaborative Group (EBCTCG). Adjuvant bisphosphonate treatment in early breast cancer: meta-analyses of individual patient data from randomised trials. Lancet 2015; 386: 1353

[26] Gnant M, Mlineritsch B, Stoeger $\mathrm{H}$ et al. Adjuvant endocrine therapy plus zoledronic acid in premenopausal women with early-stage breast cancer: 62-month follow-up from the ABCSG-12 randomised trial. Lancet Oncol 2011; 12: 631-641

[27] Coleman RE, Finkelstein D, Barrios CH et al. Adjuvant denosumab in early breast cancer: First results from international multicenter randomized phase III placebo controlled D-CARE study. J Clin Oncol 2018; 36 (Suppl.): 501

[28] Gnant M, Pfeiler G, Steger GG et al. Adjuvant denosumab in early breast cancer: Disease-free survival analysis of 3,425 postmenopausal patients in the ABCSG-18 trial. J Clin Oncol 2018; 36 (no. 15_suppl): 500. doi:10.1200/JCO.2018.36.15_suppl.500

[29] Gnant M, Pfeiler G, Dubsky PC et al. Adjuvant denosumab in breast cancer (ABCSG-18): a multicentre, randomised, double-blind, placebo-controlled trial. Lancet 2015; 386: 433-443 